\title{
The UV-C Induced Cell Death in Human Malignant Melanoma and Normal Fibroblasts
}

\author{
A. PANEK* AND A. Wieché́ \\ Institute of Nuclear Physics, PAS, E. Radzikowskiego 152, 31-342 Kraków, Poland
}

\begin{abstract}
Differences in cellular death between melanoma (Me45) cells and fibroblasts (CCL-110) were investigated after irradiation with UV-C $\left(1.5-15 \mathrm{~J} / \mathrm{m}^{2}\right)$ and incubation for up to $48 \mathrm{~h}$. The role of DNA double strand breaks in this process was assessed. Decrease of the Me45 cells viability began about $6 \mathrm{~h}$ after irradiation. The fibroblasts viability negatively correlated with the dose applied, since necrosis within this cell population began immediately after irradiation. The enhanced apoptosis of fibroblasts was observed between 6 and $24 \mathrm{~h}$, while for melanoma cells, high level of apoptotic cells was still detected after $48 \mathrm{~h}$. Statistically significant correlation between the percentage of apoptotic cells and DSBs was estimated for both cell lines. The melanoma cells responded differently to the UV-C radiation than did the fibroblasts. These differences were explained by deficiency of the necrotic processes as well as the delay of apoptotic melanoma response to UV-C damage.
\end{abstract}

DOI: 10.12693/APhysPolA.129.172

PACS: 87.50.W-, 87.14.gk

\section{Introduction}

DNA damage can be caused by exogenous agents (for example radiation, chemicals) as well as byproducts of endogenous cellular processes (for example reactive oxygen species). Generally, human cells apply three strategies to protect genomic DNA from accumulating damage (for example microdeletions, point mutation). If the damage is slight, DNA repair is attempted. The more extensive damage blocks the cell cycle progression, giving more time for DNA repair. When the repair is not successful, cells can undergo some kind of cell death. The severe damage cause that the affected cells suffer necrosis or they undergo apoptosis [1,2]. Interestingly, fragmentation of DNA, meaning high frequency of DNA double strand breaks (DSBs), is a characteristic feature for both apoptosis and necrosis processes. In this study, melanoma cells (cancer cell line) were employed to investigate the influence of UV-C exposure on cellular response (viability, apoptosis, and necrosis) in comparison to fibroblasts (normal cell line). Additionally, the contribution of DSBs detected by the presence of $\gamma$-H2AX-foci to those processes was evaluated.

The cell response to ionizing radiation and other radiomimetic agents garner a great deal of attention, however role of the UV-C in induction of DNA damage and its consequences (cell viability or death) is still not well known. The complexity of the cellular response to UV-C irradiation makes it possible for individual cells to activate an appropriate signalling/metabolic path. Then various types of cells (normal or cancer cell line) may exhibit different response to UV irradiation.

Despite the UV-C radiation does not induce DNA double strand breaks $[3,4]$ literature data indicated that

*corresponding author; e-mail: Agnieszka.Panek@ifj.edu.pl
H2AX phosphorylation was detected, during the cyclobutane pyrimidine dimers (CPD) and bulky (6-4) adducts removal after UV irradiation in quiescent cells [3]. Also it was shown that after UV-C irradiation, H2AX phosphorylation occurs in all phases of the cell cycle and is primarily displayed as a diffuse staining of the whole nucleus, called "pan-nuclear" staining $[3,5]$.

\section{Experimental protocol}

The human malignant melanoma (Me45) cell line was grown in DMEM:F12 HAM (1:1), supplemented with $12 \%$ fetal bovine albumin and $80 \mu \mathrm{g} / \mathrm{ml}$ gentamicin. This cell line was kindly provided by the Radiobiology Department of the Oncology Centre in Gliwice, Poland.

The normal human skin fibroblasts (CCL-110) cell line (the American Type Culture Collection, ATCC) was cultured in MEM medium supplemented with $20 \%$ FBS, $1 \%$ penicillin - streptomycin and $2 \mathrm{mM}$ L-glutamine. The cells from both cell lines were grown at the temperature of $37^{\circ} \mathrm{C}$ and $5 \% \mathrm{CO}_{2}$. Cells were irradiated with the $254 \mathrm{~nm}$ UV-C from a UVLS-28 lamp at a dose rate of approximately $3 \mathrm{~J} / \mathrm{m}^{2} / \mathrm{s}, 0.51 \mathrm{~mW} / \mathrm{cm}^{2}$ of energy density (CDR2 All Wave ultraviolet intensity meter). The cells were irradiated with doses: $1.5,3,9,15 \mathrm{~J} / \mathrm{m}^{2}$ of UV-C, immediately after the cell culture medium was changed and then cells were incubated up to $48 \mathrm{~h}$. Apoptotic and necrotic cells were detected in FITC-Annexin $\mathrm{V}$ and Ethidium Homodimer III-stained cells test (Biotium Inc.). The Annexin- $\mathrm{V}$ test detects changes in the cellular membrane related to the early stage of apoptosis [6]. The DNA strand breaks as pan-nuclear spots were evaluated using $\gamma$-H2AX test [5].

For each radiation dose, and the incubation time after UV-C irradiation, thousand cells were scored. Mean value and standard deviation (scanning electron microscopy, SEM) has been evaluated for each set of data. The Pearson correlation, ANOVA with post-hoc TurkeyKramer Multiple Comparisons were performed with the Statistica 8.0 software. 


\section{Results and discussion}

The variations in viability of fibroblasts were statistically significant (decrease to $6 \mathrm{~h}$ and later increase to $48 \mathrm{~h}$ ). The melanoma cells viability slowly decreased up to $48 \mathrm{~h}$ after irradiation (Fig. 1). Low number
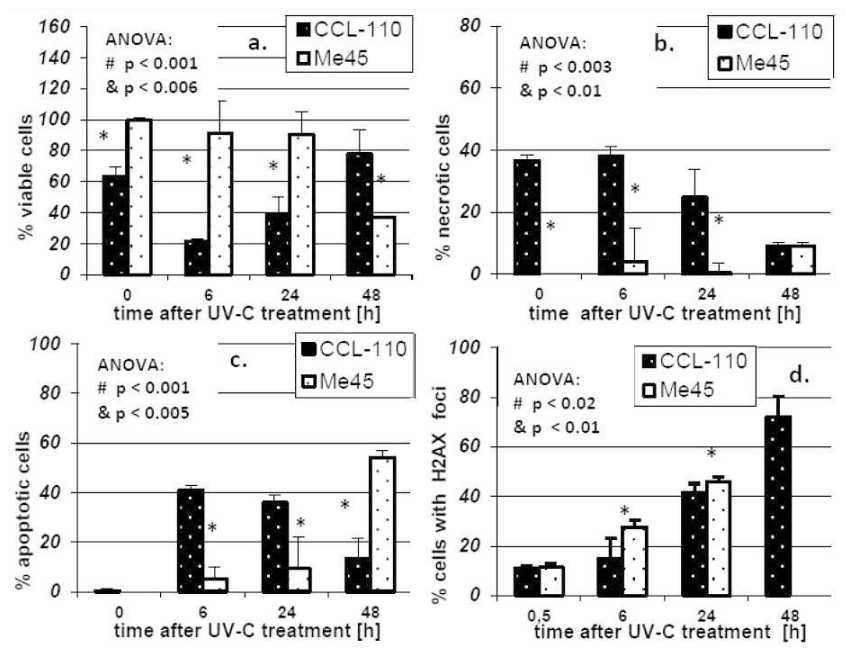

Fig. 1. The cellular response of melanoma (Me45) and fibroblast (CLL-110) cells for $9 \mathrm{~J} / \mathrm{m}^{2}$ of UV-C irradiation ((a) living cells, (b) necrosis, (c) apoptosis and (d) $\gamma$-H2AX foci-positive cells).

of dead melanoma cells after UV irradiation found by Kobayashi et al. [7] was explained by presence of the intracellular melanin and its role in preventing UV induced cell killing by reducing the formation of DNA damage [7]. The limited access to damaged DNA due to the presence of melanin might be the reason for the delay of melanoma cells response to UV-C irradiation in our study. As expected, in this study necrosis turned out to be the first observed type of CCL-110 cell death after UV$\mathrm{C}$ treatment. The process proved to be dose-dependent $(r=0.93, p<0.01)$ and took place during the first $6 \mathrm{~h}$ after UV-C irradiation in these cells. In melanoma cells, however, necrosis did not contribute to cellular response to the UV-C damage induction. Six hours after UV-C irradiation the apoptosis was a dominant type of death in both cell lines. The increase of apoptotic melanoma cells in time was found to be statistically significant. In fibroblast cells the intensification of apoptosis processes occurred after $24 \mathrm{~h}$, and then the percentage of apoptotic cells began to decline. Others results for various melanoma cell lines $[8,9]$ showed that the DNA damage induced by UV-C $\left(50 \mathrm{~J} / \mathrm{m}^{2}\right)$ caused growth arrest and, eventually, the apoptotic response. The collapsed replication fork in response to UV photoproducts generates DSBs [10], and non-repaired DSBs may trigger apoptosis $[5,11]$. That is why the involvement of DNA DSBs in cell death processes was investigated in this study. The number of $\gamma-\mathrm{H} 2 \mathrm{AX}$ foci-positive cells significantly increased with incubation time for both types of cells.
Figure 1 presents cellular response for $9 \mathrm{~J} / \mathrm{m}^{2} \mathrm{UV}-\mathrm{C}$ dose, however similar results were obtained for others: $1.5,3$, $15 \mathrm{~J} / \mathrm{m}^{2} \mathrm{UV}-\mathrm{C}$ doses. The Pearson correlation analysis showed a significantly positive correlation between DSBs and the number of apoptotic cells $(r=0.87, p<0.05$ for fibroblasts and $r=0.92, p<0.01$ for melanoma cells), and no correlation between the DSB appearance and the necrotic processes. These results were consistent with literature data [10] in that the DSBs formation was involved with the apoptosis.

In conclusion, the melanoma Me45 cell response to the UV-C irradiation was different in comparison to the fibroblast CCL-110 cells. Results indicated necrosis processes disorders and delay of apoptosis in melanoma cells after UV-C-damage induction. The DNA DSBs were agents triggering apoptosis in the melanoma cells as well as in the fibroblasts.

\section{Acknowledgments}

The authors are grateful to Professor Maria Wideł from Silesian University of Technology, in Gliwice for providing the Me45 cell line established by herself.

\section{References}

[1] V. Clément, I. Dunand-Sauthier, S.G. Clarkson, Cell Death Differ. 13, 478 (2006).

[2] A.W. Farrell, G.M. Halliday, J.G. Lyons, Int. J. Mol. Sci. 12, 8063 (2011).

[3] T.M. Marti, E. Hefner, L. Feeney, V. Natale, J.E. Cleaver, Proc. Natl. Acad. Sci. USA 103 , 9891 (2006).

[4] K. Rass, J. Reichrath, Adv. Exp. Med. Biol. 624, 162 (2008).

[5] J.E. Cleaver, Photochem. Photobiol. 87, 1230 (2011).

[6] G. Gobe, C. Winterford, in: Apoptosis, Ed. V.E. Preedy, Science Publ., Enfield 2010, p. 621.

[7] N. Kobayashi, T. Muramatsu, Y. Yamashina, T. Shirai, T. Ohnishi, T. Mori, J. Invest. Dermatol. 101, 685 (1993).

[8] H.T. Wang, B. Choi, M.S. Tang, Proc. Natl. Acad. Sci. USA 107, 12180 (2010).

[9] T. Haapajarvi, K. Pitkanen, M. Laiho, Cell Growth Differ. 10, 163 (1999).

[10] T.R. Dunkern, B. Kaina, Mol. Biol. Cell 13, 348 (2002).

[11] W.P. Roos, B. Kaina, Trends Mol. Med. 12, 440 (2006). 